\title{
Industry 4.0 roadmap for SMEs: validation of moderation techniques for creativity workshops
}

\section{Riccardo Brozzi}

Fraunhofer Italia Research s.c.a.r.l., Innovation Engineering Center (IEC), 39100 Bolzano, Italy

Email: riccardo.brozzi@fraunhofer.it

\section{Erwin Rauch*}

Faculty of Science and Technology,

Free University of Bozen-Bolzano,

Universitätsplatz 1, 39100 Bolzano, Italy

Fax: +390471017009

Email: erwin.rauch@unibz.it

${ }^{*}$ Corresponding author

\section{Michael Riedl}

Fraunhofer Italia Research s.c.a.r.1., Innovation Engineering Center (IEC), 39100 Bolzano, Italy

Email: michael.riedl@fraunhofer.it

\section{Dominik T. Matt}

Fraunhofer Italia Research s.c.a.r.l., Innovation Engineering Center (IEC), 39100 Bolzano, Italy

and

Faculty of Science and Technology, Free University of Bozen-Bolzano, Universitätsplatz 1, 39100 Bolzano, Italy

Fax: +390471 017009

Email: dominik.matt@fraunhofer.it

Email: dominik.matt@unibz.it 
Abstract: Industry 4.0 is an element of entrepreneurial strategy to survive to rapidly and constantly changing markets. Several studies acknowledge that small and medium sized enterprises (SMEs) face challenges initiating innovation processes towards digital transformation. However, the success of the so called fourth industrial revolution will ultimately depend on whether SMEs can adopt and implement these technologies, as they represent the backbone of numerous economies worldwide. The present study aims at presenting the characteristics of a roadmap service supporting SMEs in the manufacturing and building sector throughout the technological and organisational planning of Industry 4.0 in their business strategies. The results of a social experiment to validate the selected design thinking techniques show that most of them enable innovation dynamics in creativity workshops for Industry 4.0 roadmaps and are useful for deriving an implementation plan for Industry 4.0 in SMEs.

Keywords: Industry 4.0; roadmap; self-assessment; readiness; maturity model; SMEs; small and medium sized enterprises.

Reference to this paper should be made as follows: Brozzi, R., Rauch, E., Riedl, M. and Matt, D.T. (2021) 'Industry 4.0 roadmap for SMEs: validation of moderation techniques for creativity workshops', Int. J. Agile Systems and Management, Vol. 14, No. 2, pp.276-291.

Biographical notes: Riccardo Brozzi is scientific collaborator at Fraunhofer Italia Research in Bolzano, Italy. His main research interest is in business modelling, management engineering, technology management and agile systems engineering.

Erwin Rauch is an Assistant Professor of Manufacturing Technology and Systems at the Faculty of Science and Technology at the Free University of Bolzano (Italy). He studied at the Free University of Bolzano, at the Technical University in Munich and got his $\mathrm{PhD}$ at the University of Stuttgart. His main research interests are in agile manufacturing systems design, Industry 4.0, sustainable manufacturing, distributed manufacturing, production planning and control in MTO and ETO enterprises and axiomatic design. He is also head of the smart mini-factory laboratory for Industry 4.0 in SMEs.

Michael Riedl is Deputy Head of Fraunhofer Italia Research and is responsible for the research area Automation and Mechatronics Engineering. His research focus is on applied research in the field of intelligent and modular production systems.

Dominik T. Matt holds the Chair for Production Systems and Technologies and Heads the research department "Industrial Engineering and Automation (IEA)" at the Faculty of Science and Technology at the Free University of Bozen-Bolzano. Moreover, he is the Director of the Research Center Fraunhofer Italia in Bolzano. He has authored more than 200 scientific and technical papers in journals and conference proceedings and is member of numerous national and international scientific organisations and committees. 


\section{Introduction}

The continuous pressures on the technological advancement of enterprises regarding the introduction of Industry 4.0 requires the adaptation of traditional strategies and instruments in order to support the successful implementation of the Fourth Industrial Revolution. Small and medium sized enterprises (SMEs) are of particular interest for this research, which are the backbone of the economy in many countries (European Commission, 2018). European micro, small and medium sized enterprises provide around $45 \%$ of the value added by manufacturing while they provide around $59 \%$ of manufacturing employment (Vidosav, 2014). Also in the US SMEs account for nearly two-thirds of net new private sector jobs in recent decades (Office of the United States Trade Representative, 2017).

It remains essential for both types of enterprises, large enterprises as well as SMEs, to know the tools needed to best respond to the challenge of Industry 4.0. Systematic approaches, better known as 'strategic roadmaps', play a major role in the introduction of new concepts (Blackwell et al., 2008). Therefore also the implementation of new strategies for the digital transformation of an enterprise should be facilitated and supported by the use of 'Industry 4.0 roadmaps' (Pessl et al., 2017).

This research aims to analyse in a first step existing roadmaps in the literature. Subsequently, methodological roadmaps will be explored in more detail. The theme of Industry 4.0 represents an element of total innovation for today's companies: processes, techniques, products and business models require to be conceived in a completely different way than what happened traditionally. The various processes for generating creative and innovative ideas include the design thinking methodology. The new creative way of thinking oriented to problem-solving draws its origins from David Kelley from the School of Design of Stanford University in the early 1990s (IDEO, 2018). The literature review focuses in particular on the methods of Design Thinking as a basis for the analysis and evaluation of various moderation techniques. The discussion on the methodologies will allow the outline of the characteristics of a new Industry 4.0 roadmap service that intends to address especially SMEs, which often lag behind large companies due to scarcity of financial and human resources as well as a lack of structures for research and development.

In this work two research questions will be answered:

- RQ1: What is the state of the art in Industry 4.0 roadmap models?

- RQ2: Which techniques within the design thinking have a stronger application potential in Industry 4.0 roadmaps for SMEs?

The paper is structured as follows. After a first introduction, a short literature review summarises the actual state of the art of roadmaps for the introduction of Industry 4.0. Next follows the description of the research method. Then the authors describe the proposed Industry 4.0 roadmap service for SMEs and a selection and validation of design thinking moderation techniques. In order to test the developed roadmap service and in particular the selected moderation techniques for the creativity workshop in the proposed Industry 4.0 roadmap service, the results of a case study based on a social experiment are shown. After a critical discussion, the paper ends with a conclusion and an overview of future directions regarding methods and instruments for the introduction of Industry 4.0 in companies and especially in SMEs. 


\section{State of the art in roadmaps for Industry 4.0}

A technology roadmap is defined as a tool used by organisations to provide the information needed to make technology investment decisions by identifying critical technologies and gaps that require further research and development (Santos et al., 2017). The roadmapping technique emerged based on the needs from industry. One of the first to apply roadmaps was Motorola (Willyard and McClees, 1997), with the method widely adopted within the company as a central part of the business planning process, and being extended to supply chain and industry-level application (Probert et al., 2003). In the early 1990s technology roadmaps crossed company boundaries, involving analysis and forecasting of technological and product trends relating to the industrial world as a whole. Technological-strategic roadmaps, which contain all the specifications and target values for the definition and implementation of future strategies (Galvin, 1998). In the 2000s the first discussions about 'disruptive technologies' start and lead to a need for reviewing the technological roadmaps at a global industrial level predicting the variations of the technological trends (in these years e.g. microsystems, nanotechnologies, micromachining) in a very short time and to be able to respond adequately to them (Walsh, 2004). Finally, in 2011 the creation of the term 'Industry 4.0' (Kagermann et al., 2013) led scholars and consulting companies gradually to start the development of methodological roadmaps ready to be used to introduce the new theoretical and technological principles in the individual enterprise. The reason for this is that the complex conception of Industry 4.0 requires to channel much of the effort towards the systematic learning of new technologies and new models of business. The roadmaps for Industry 4.0 identified in this literature review are now examined in more detail.

Depending on the initiator of roadmap development, different types of roadmaps for Industry 4.0 can be identified in the literature. Table 1 provides an overview of existing roadmaps found in literature and categorising them in institutional (I), consulting (C) and scholarly (S) roadmaps. In the following we will give some more details to these three types of roadmaps.

Over the years, the European Union as well as other institutions have financed a series of programs and actions whose results can be widely used to enhance technological evolution, especially in the industrial sector (SETIS, 2018). The introduction of Industry 4.0 has further accelerated the need to define technology trends and to promote a change in industry vs. new and emerging technologies (Santos et al., 2017). The meaning of 'institutional roadmaps' refers to the guidelines provided by the European Union, defined as strategic technology roadmaps. In addition to the European Union also associations of several countries developed strategic roadmaps for Industry 4.0. The German Engineering Federation VDMA published a document with guidelines for the implementation of Industry 4.0 in small and medium sized enterprises (VDMA, 2018). The various roadmaps are scientifically based as the various projects have been carried out by scientists or developed with the involvement of scientific advisory boards. However, the recommendations for action often have a still very abstract level, provide only rough guidelines and are rarely directly applicable in industrial companies. 
Table 1 Identified roadmaps in literature related to Industry 4.0 technologies

\begin{tabular}{|c|c|c|}
\hline Source & Identified roadmaps in the literature review & $\begin{array}{c}\text { Type } \\
I=\text { Institutional } \\
C=\text { Consulting } \\
S=\text { Scholarly }\end{array}$ \\
\hline VDMA (2018) & VDMA Guideline Industry 4.0 & I \\
\hline EPoSS (2018) & $\begin{array}{l}\text { Strategic Research Agenda of the European } \\
\text { Technology Platform on Smart Systems Integration } \\
2017\end{array}$ & I \\
\hline EFFRA (2016) & $\begin{array}{l}\text { Factory of the Future roadmap - Work program } \\
\text { developed by EFFRA (European Factories of the } \\
\text { Future Research Association) }\end{array}$ & I \\
\hline Pathfinder (2018) & $\begin{array}{l}\text { Pathfinder Roadmap: defining research priorities to } \\
\text { drive R\&D activities in the Simulation and } \\
\text { Forecasting Technologies (S\&FT) }\end{array}$ & I \\
\hline IMS2020 (2018) & $\begin{array}{l}\text { IMS2020 Roadmap on Sustainable Manufacturing, } \\
\text { Energy Efficient Manufacturing and Key } \\
\text { Technologies }\end{array}$ & I \\
\hline ActionPlanT (2018) & $\begin{array}{l}\text { ActionPlanT of the European Forum for ICT in } \\
\text { Factories of the Future }\end{array}$ & $\mathrm{I}$ \\
\hline SPARC (2018) & $\begin{array}{l}\text { Robotics } 2020 \text { Multi-Annual Roadmap from the } \\
\text { European partnership for robotics SPARC }\end{array}$ & $\mathrm{I}$ \\
\hline ARTEMIS (2018) & $\begin{array}{l}\text { ARTEMIS roadmap: European Roadmap for } \\
\text { Industrial Process Automation }\end{array}$ & I \\
\hline KPMG (2017) & KPMG Industry 4.0 Roadmap & $\mathrm{C}$ \\
\hline $\begin{array}{l}\text { Capgemini Consulting } \\
\text { (2014) }\end{array}$ & Capgemini Consulting Roadmap for Industry 4.0 & $\mathrm{C}$ \\
\hline $\begin{array}{l}\text { Innovationszentrum für } \\
\text { Industrie } 4.0(2018)\end{array}$ & $\begin{array}{l}\text { Pathfinder i } 4.0 \text { by Innovationszentrum für Industrie } \\
4.0\end{array}$ & $\mathrm{C}$ \\
\hline AgiPlan (2018) & AgiPlan Industry 4.0 Roadmap & $\mathrm{C}$ \\
\hline Ero et al. (2016) & $\begin{array}{l}\text { Industry 4.0 Three Stage Process Model (Authors: } \\
\text { Selim Erol, Andreas Schumacher, Wilfried Sihn) }\end{array}$ & $\mathrm{S}$ \\
\hline $\begin{array}{l}\text { Merz and Siepmann } \\
(2016)\end{array}$ & $\begin{array}{l}\text { Industry } 4.0 \text { - Procedure model for the introduction by } \\
\text { Sandra Lucia Merz and David Siepmann }\end{array}$ & $\mathrm{S}$ \\
\hline Hermann et al. (2016) & $\begin{array}{l}\text { Industry 4.0 Project Roadmap by Mario Hermann, } \\
\text { Tobias Pentek and Boris Otto }\end{array}$ & $\mathrm{S}$ \\
\hline Cho et al. (2016) & $\begin{array}{l}\text { Industrial Technology Roadmap by Yonghee Cho, } \\
\text { Seong-Pil Yoon and Karp-Soo Kim }\end{array}$ & $\mathrm{S}$ \\
\hline Seiter et al. (2016) & $\begin{array}{l}\text { Roadmap Industry } 4.0 \text { by Mischa Seiter, Christoph } \\
\text { Bayrle, Sebastian Berlin, Ute David, Marc Rusch and } \\
\text { Oliver Treusch }\end{array}$ & $\mathrm{S}$ \\
\hline Matt et al. (2018) & $\begin{array}{l}\text { Five-Step Methodology to Introduce Industry } 4.0 \text { by } \\
\text { Dominik T. Matt, Erwin Rauch and Michael Riedl }\end{array}$ & $\mathrm{S}$ \\
\hline Pessl et al. (2017) & $\begin{array}{l}\text { Roadmap Industry } 4.0 \text { by Ernst Pessl, Sabrina Romina } \\
\text { Sorko and Barbara Mayer }\end{array}$ & $\mathrm{S}$ \\
\hline Ghobakhloo (2018) & $\begin{array}{l}\text { Strategic Roadmap towards Industry } 4.0 \text { by Morteza } \\
\text { Ghobakhloo }\end{array}$ & S \\
\hline
\end{tabular}


The consulting world today offers numerous services in terms of business action plans, especially in the area of Industry 4.0. A very valuable tool is the KPMG 'Industry 4.0 strategic roadmap', which proposes a very simple action plan with three main steps: (1) definition of a real roadmap based on an assessment of technological and financial maturity, (2) preparation of a pilot project and (3) implementation (KPMG, 2017). The consultancy activity of the Capgemini Consulting group in Industry 4.0 proposes a roadmapping tool whose common thread is the theme of digitisation, aimed at manufacturing companies. The circular roadmapping procedure consists of six consecutive steps: (1) digital maturity assessment, identification of opportunities and threats, Industry 4.0 vision, prioritisation, Industry 4.0 action plan, implement and sustain the change (Capgemini Consulting, 2014). Another three-step tool is 'Pathfinder i4.0', an action plan drawn up by the German consulting firm Innovationszentrum für Industrie 4.0 consisting of (1) a self-assessment compiled online, (2) a workshop session for the evaluation of the current state of the enterprise and (3) finally the compilation of a practical roadmap (Innovationszentrum für Industrie 4.0, 2018). Also the roadmap of AgiPlan (2018) follows a similar procedure as the other consulting approaches. All the previously described consulting procedures show a certain lack of scientific methodology to identify Industry 4.0 concepts and their applicability and potential in the company as they are mostly based on workshop discussions and expert opinions of consultants.

The third category of roadmapping tools for Industry 4.0 are scientifically based methodical roadmaps. These roadmaps are of particular interest, especially for the exploitation and transfer of Industry 4.0 concepts from research to practice in SME industry, leaving aside national or supranational strategies that are too complex and disconnected from the reality of a company (as happens probably with institutional roadmaps) and grounding on a scientifically consistent basis (in contrast to consulting roadmaps).

\section{Methodology}

\subsection{Method for the development of the I4.0 roadmap service for SMEs}

The framework methodology employed to develop the I4.0 roadmap service mainly comprised five phases. As seen in Section 2, in the first phase (Literature Review), the results of a literature review summarise requirements of SMEs regarding the introduction of innovation processes as well as the main existing roadmapping methods categorising them in institutional roadmaps, consulting roadmaps and scholarly roadmaps for the digital transformation in industrial companies. Since the I4.0 Roadmap project aims at developing a roadmap service in terms of a methodological support for innovation processes with the focus on SMEs, the analysis of identified methods and approaches has been emphasised on best practices for their application in SMEs. In this regard, such roadmaps offer a wide range of methodological inputs to be evaluated in the context of SMEs. In the second phase (SWOT Analysis), a strength, weaknesses opportunity and threats (SWOT) Analysis (Houben et al., 1999) has been formulated as qualitative method to evaluate the adequacy of the different methods and approaches proposed in existing examples of roadmaps and main challenges faced by SMEs in managing innovation processes previously collected. In the third phase, (Identification Moderation Techniques) the authors conducted a literature review focusing on moderation techniques 
and methods in the framework of Design Thinking e.g. for the generation of innovative ideas as well as the definition of requirements and fields of application of Industry 4.0 concepts in the company. In the fourth phase (Development I4.0 Roadmap Service), the proposed I4.0 Roadmap service was developed by the research team, considering only selected methods showing higher application potential for SMEs. The techniques and methods were adapted to make their content and structure more tailored to the needs and capabilities of SMEs. Finally, in the last phase (Expert Interviews) expert interviews with representatives from industrial associations and business development agencies were conducted to confirm the usefulness of the proposed I4.0 Roadmap service and to collect feedback on the overall validity of the research outcomes for industry. Semi-structured interviews with local experts consisting of predefined open, multiple choice and Likertscale questions lasted on average 60 minutes.

\subsection{Social experiment to test and validate the adequacy of the I4.0 roadmap service}

A selection of collected methods and moderation techniques in the framework of design thinking emerging from the literature review were simulated in a controlled research environment during a hypothetical moderation of a workshop in the company. The essential aim of the simulation was to test the validity and adequacy of selected design thinking methodologies, to practice and refine specific moderation techniques which will be proposed in real SMEs environments. The fictitious company taking part to the design thinking workshop part of the I4.0 Roadmap service was supposed to be a SMEs dedicated to steel processing in engineer-to-order (ETO) form. With respect to the main reasons justifying the request of the workshop by the company, three main issues were considered, namely the possibility to monitoring tools used in production, real-time updating of material availability in the warehouse, and frequent machine downtimes due to the several production cycle changes. In this regard, the selected design thinking moderation techniques should serve to better understand the real requirements of the company, generate innovative ideas and evaluate a first set of feasible solutions to be further developed and implemented in the short, medium and long term. The simulation took place at the authors' research affiliation involving internal staff members, who had previously been assigned a company role and character to play during the different parts of the workshop, to make the interaction as much real as possible. The roles assigned to the participants were the company managing director, production and logistics manager, IT manager and head of accounting. Besides their role, a brief description of their attitudes toward digital transformation was outlined. The attitudes toward digitalisation were assigned to have a mixed audience of subjects with different degrees of knowledge, openness and empathy toward Industry 4.0, process innovation and collaboration with external experts respectively. These aspects were considered on purpose since SMEs results particularly sceptical about Industry 4.0 application and technology strategy that they are still unfamiliar with (Kagermann et al., 2013). Furthermore, conflicting attitudes emerging due to the lack of a clear vision on digitalisation issues (Schröder, 2017), deserve to be considered and retain an influence in the dynamics between researchers and company members, e.g., during the moderation of workshops. At the end of the workshop each member had the possibility to rate the degree of usefulness and innovativeness of the technique employed during the workshop as well as providing general feedback on the quality of the moderation and structure of the workshop. The evaluation of the 
workshop was carried out via a survey composed of questions displaying a 0 (strongly disagree) to 100 (strongly agree) point scale and open questions for general feedback.

\section{$4 \quad$ I4.0 roadmap service for SMEs}

\subsection{Framework of the developed I4.0 roadmap service}

The literature review outlined several challenges to be considered in the design and selection of roadmap services for SMEs and moderation techniques. The main challenges of SMEs identified in the literature review are:

- difficulties in the timely identification of important technological trends (Placzek et al., 2015)

- $\quad$ lack of knowledge regarding I4.0 potential for the production domains (Koska et al., 2017)

- $\quad$ proper skills of workers (Karre et al., 2017)

- $\quad$ lack of a clear strategic vision (Eckelt et al., 2016)

- $\quad$ adequate resources to adapt their current business strategies to I4.0 (Cerchione and Esposito, 2017).

On the base of the collected challenges, the authors carried out a SWOT analysis of existing roadmaps from Section 2 (see Table 2). The main emerging limits regarding the adequacy of the I4.0 Roadmap service for SMEs identified lies in the complexity of certain tools proposed, e.g., for the evaluation of potential application scenarios, for the knowledge transfer of Industry 4.0 as well as for the applicability across different sectors. The degree of comprehensiveness of the service, e.g., presence of several service phases may also be a limiting factor for the time and human resource availability of SMEs.

Table 2 SWOT analysis of existing roadmaps

\begin{tabular}{ll}
\hline Strengths & Weaknesses \\
Practical case studies & Lack of reference to SMEs \\
Technology set-up demonstrator & Strong sectorial focus \\
$\begin{array}{l}\text { Best practice examples } \\
\text { Digital level assessment }\end{array}$ & Limited knowledge transfer on I4.0 topics \\
Involvement of several managerial levels & \\
Opportunities & \\
Innovative creative techniques & Threats \\
Re-evaluation of identified scenarios & Scalability to SMEs \\
Modular structure & Lack of digital level assessment \\
\hline
\end{tabular}

Based on the found above mentioned challenges of SMEs towards digitalisation, strengths and weaknesses of identified road-mapping services and experts interviews (as explained in Section 3) the following Industry 4.0 Roadmap service with a total of five phases was derived (Figure 1). 
Figure 1 Developed I4.0 roadmap service

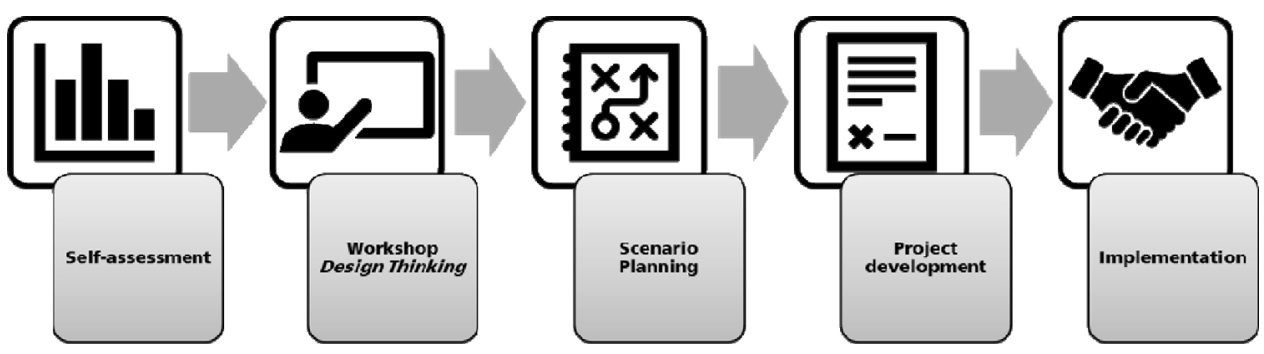

The first phase of the developed I4.0 Roadmap service (Self-Assessment) consists of a self-assessment survey to identify the digital level and overall existing challenges faced by the company in the main production and organisation processes. The decision to include the assessment was undertaken since identifying the digital level of an SME results fundamental prior to the definition of any I4.0 initiative or an implementation of Industry 4.0 technologies or concepts.

In the second phase (Design Thinking Workshop), according to the results of the assessment and therefore to the digital level of the assessed SME, an expert workshop is held in the company. The workshop serves for knowledge transfer on digital transformation topics and for the identification of specific requirements in terms of digitalisation and automation of production or organisation processes. The workshop is conceived to close the information gap of SMEs on digital transformation and advanced automation topics, following the emerging evidence from literature and the SWOT analysis. This phase foresees innovative moderation techniques belonging to the design thinking methodology in order to analyse problems in the company and to derive possible solutions using Industry 4.0 concepts. The workshop itself consists of five steps:

- Step 1: Discussion and structuring of problems in the company

- Step 2: Detailing of specific problems identified in the group

- $\quad$ Step 3: Brainstorming of possible Industry 4.0 solutions

- Step 4: Improvement of identified ideas/solutions

- Step 5: Selection of ideas/solutions.

The approach for the selection and validation of the most useful and creativity supporting moderation techniques according to the identified SWOT criteria is described in Sections 4.2 and 4.3 .

In the third phase (Scenario Development) The I4.0 Roadmap service is completed by the derivation of scenarios for the digital transformation in line with the individually identified company requirements. The scenarios developed by the experts consider different degrees of digital transformation indicating main advantages and drawbacks and thus supporting a successful integration in existing processes.

After the validation and selection of most promising scenarios, the company receives in the fourth phase (Project Development) a proposal for an implementation project indicating specific objectives, expected results, internal resources needed and the necessary time-frame for the implementation. 
In the fifth phase (Implementation) the SME implements the defined Industry 4.0 project supported by the external experts.

\subsection{Selection of design thinking techniques for the creativity workshop}

Industry 4.0 represents an element of total innovation for today's companies: processes, techniques, products and business models need to be conceived in a completely different way than it was traditionally the case. In order to define the right steps for introducing Industry 4.0 in an SME, the I4.0 Roadmap service described before foresees as creative workshop in the company moderated with the help of external experts.

Among the different possibilities for generating creative and innovative ideas the methodology design thinking is well known. Design thinking is a comprehensive meta-disciplinary concept that broadens disciplinary reasoning (Lindberg et al., 2011). The problem-solving oriented creative way of thinking was originated at Stanford University School of Design in the early 1990s (Camacho, 2016). Among the proponents of this technique is David Kelley, founder of the innovation company IDEO and the Hasso Plattner Institute of Design, part of the Design faculty of Stanford University (Camacho, 2016). The two main concepts on which Design Thinking is based concern the centrality, in the decision-making process, of the person as an active participant and as an end customer. Anyone who participates in a creative process in the style of design thinking enjoys an essential position as a creative individual and a driving force behind the entire process (human-centred perspective) (Camacho, 2016).

From the existing techniques of design thinking retrievable from literature, five techniques have been selected by the research team according to their high compliance and matching with specific SWOT criteria retrieved from literature on Industry 4.0 roadmaps. Table 3 shows the selected techniques employed for the validation within the I4.0 roadmap service.

\subsection{Results of the social experiment to test and validate design thinking techniques}

As explained in the Section 3.2, the developed I4.0 Roadmap service and in particular the previously defined design thinking techniques for the creative workshop (second phase of the service) were tested in a social experiment, where collaborators of the authors research group simulated a real workshop situation in a typical SME of the steel and construction sector. Participating collaborators took over a defined role in the company (e.g., CEO, production manager, logistics manager, etc.) and mentally putted themselves in the assigned role.

After the social experiment participants, apart from the moderator, ranked the proposed design thinking techniques in a graph according to their usefulness ( $x$-axis) and degree of innovation ( $y$-axis). Such variables were defined in terms of capacity for the participant to apply in the short term the information gained using an individual technique (usefulness) and the perception of interaction dynamics and creativity among participants (innovation). Most of the techniques used were considered useful and with a moderate level of innovation (Figure 2). The use of the technique 'Mind Map' was considered the most useful in terms of information and linkages collected to tackle the specific problem considered, followed by 'Observe', 'Decision Matrix' and 'How Might We' Although the technique 'SCAMPER' shows a similar support in creativity and 
innovation it has been assessed as less useful as the other methods due to its complexity to apply it in SME workshops.

Table 3 Matching of design thinking techniques with SWOT criteria

\begin{tabular}{|c|c|c|c|}
\hline SWOT criteria & $\begin{array}{l}\text { Design thinking } \\
\text { techniques }\end{array}$ & Step in the workshop & Short description \\
\hline Modular structure & $\begin{array}{l}\text { Mind Map } \\
\text { (Tschimmel, 2012) }\end{array}$ & $\begin{array}{l}\text { Step } 1 \text { - Discussion and } \\
\text { structuring of problems } \\
\text { in the company }\end{array}$ & $\begin{array}{l}\text { Brainstorming process aimed at } \\
\text { setting hierarchies and relationship } \\
\text { across digital and automation } \\
\text { requirements of the company in } \\
\text { different units. }\end{array}$ \\
\hline $\begin{array}{l}\text { Practical case } \\
\text { study/demonstrator }\end{array}$ & $\begin{array}{l}\text { Observe (Curedale, } \\
\text { 2018) }\end{array}$ & $\begin{array}{l}\text { Step } 2 \text { - Detailing of } \\
\text { specific problems } \\
\text { identified in the group }\end{array}$ & $\begin{array}{l}\text { Detailed observation of concepts in } \\
\text { real context examples, e.g., video }\end{array}$ \\
\hline $\begin{array}{l}\text { Innovative creative } \\
\text { technique }\end{array}$ & $\begin{array}{l}\text { How Might We...? } \\
\text { (Glen et al., 2015) }\end{array}$ & $\begin{array}{l}\text { Step } 3 \text { - Brainstorming } \\
\text { of possible Industry } 4.0 \\
\text { solutions }\end{array}$ & $\begin{array}{l}\text { Aims to deepen the range of } \\
\text { solutions iterating the "How might } \\
\text { we" questions starting from a real } \\
\text { case company problem. }\end{array}$ \\
\hline $\begin{array}{l}\text { Re-evaluation of } \\
\text { scenarios }\end{array}$ & $\begin{array}{l}\text { SCAMPER (Serrat, } \\
\text { 2017) }\end{array}$ & $\begin{array}{l}\text { Step } 4 \text { - Improvement } \\
\text { of identified } \\
\text { ideas/solutions }\end{array}$ & $\begin{array}{l}\text { Facilitate idea refinement } \\
\text { considering acronym actions } \\
\text { namely Substituting-Combining- } \\
\text { Adapting-Modifying-Putting-to- } \\
\text { another-use, Eliminating and } \\
\text { Reversing elements characterising } \\
\text { the generated set of ideas and } \\
\text { solutions to a company problem. }\end{array}$ \\
\hline $\begin{array}{l}\text { Complexity of } \\
\text { evaluation processes }\end{array}$ & $\begin{array}{l}\text { Decision Matrix } \\
\text { (Seram, 2013) }\end{array}$ & $\begin{array}{l}\text { Step } 5 \text { - Selection of } \\
\text { ideas/solutions }\end{array}$ & $\begin{array}{l}\text { Support to idea ranking and } \\
\text { selection according to expected } \\
\text { effort for the implementation and } \\
\text { priority level for the company. }\end{array}$ \\
\hline
\end{tabular}

Figure 2 Validation of selected design thinking techniques (see online version for colours)

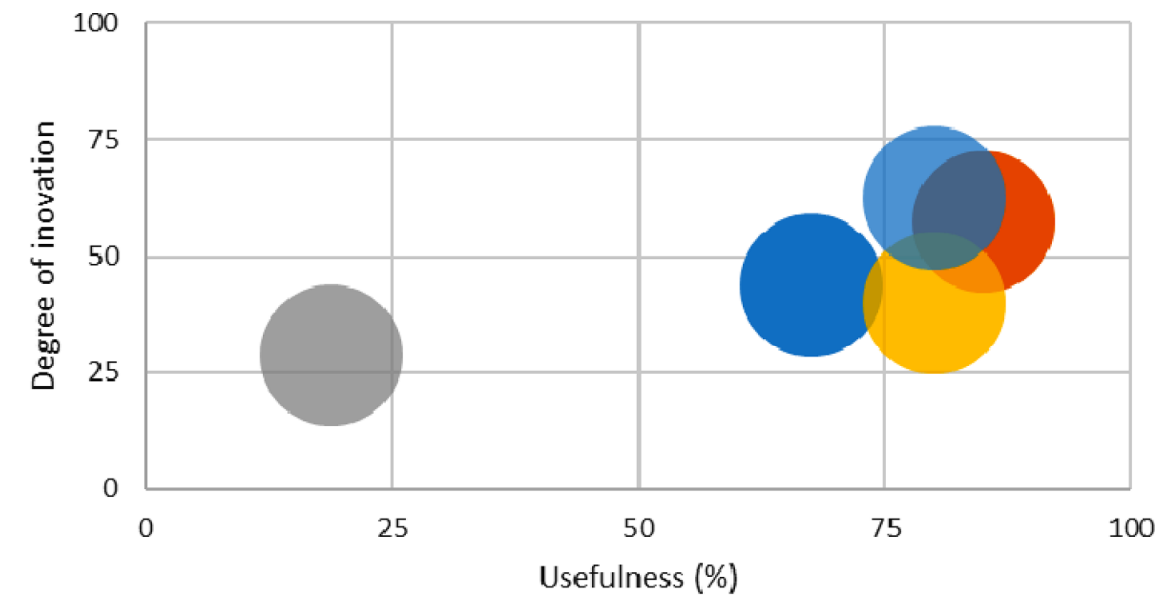

- How Might We? - Mind map - SCAMPER Decision matrix - Observe 


\section{Discussion}

Knowledge transfer activities are essential to support SMEs overcoming the major challenges they face in the planning of lean and agile Industry 4.0 concepts in their production and organisational process (Aziz et al., 2019; Rauch et al., 2017; Rauch et al., 2017). The identification of innovative techniques stimulating creativity may facilitate the generation of novel ideas and approaches, ultimately improving the capacity of SMEs to develop digital roadmaps. Such creativity techniques help to consider also the specific human requirements of employees and other stakeholders (Ceccacci et al., 2019) aiming for social sustainability in SME factories (Papetti et al., 2020; Matt et al., 2020). In this research, we analysed selected design thinking techniques for the creative and systematic generation and evaluation of ideas. Through the simulation of applying such techniques in practice with SMEs and the evaluation of their innovativeness and usefulness, we tried to short list those techniques with higher potential of application in the context of SMEs. The results show that the majority of the techniques analysed are mature for being applied in road-mapping services for SMEs. Other techniques such as SCAMPER were assessed as less useful as their application may require further knowledge of the contents and practice in the moderation prior being performed with companies. The evaluation of techniques presented in this study relies on the evaluation of research teams having as reference their experience in conducting applied research projects with SMEs. On the one hand, this aspect can be considered a major limitation of this research pretending to derive impactful results for SMEs. On the other hand, such a preliminary step is necessary, to filter out those techniques that may have a lower impact for SMEs. This may also encourage the participation of companies to the evaluation of techniques, which may already retain an impact during real case study simulation. In this regard, future developments of the research require defining more detailed metrics SMEs should employ in evaluating such techniques.

\section{Conclusion and outlook}

This work gives a first very important contribution by presenting an overview of the Industry 4.0 roadmapping approaches currently available in the literature. A breakdown into roadmaps is provided, which have been developed by institutions, consulting firms and scientists. This overview should summarise current results of the scientific literature as well as the methods used by practitioners and policy makers.

Based on the literature research, the challenges and requirements of SMEs for the introduction of Industry 4.0 concepts were also examined. Based on these challenges and the identified Industry 4.0 roadmaps, a SWOT analysis was conducted to identify best practices of existing models and at the same time to identify weaknesses and limits of existing models. The findings of the SWOT analysis as well as discussions with experts from practice formed the basis for the development of an Industry 4.0 roadmap service for SMEs.

In one of its steps, this service also includes the conduction of a creativity workshop to analyse the problems in SMEs and to derive ideas and solutions by using Industry 4.0. These ideas should ultimately result in Industry 4.0 introductions in SMEs. As a second important contribution, the present paper shows a proposal for the design of such a creativity workshop on the basis of moderation methods from the Design Thinking 
school. Selected moderation methods were tested and validated by means of an experiment and mostly all of them showed a great potential to be used in practice.

In a next step the research team will conduct a series of real industrial case study test applying the proposed I4.0 Roadmap service to SMEs. Through a satisfaction survey as well as feedback discussions the authors will analyse the usefulness and perceived degree of innovation of the proposed design thinking methods. Especially for the application of the method SCAMPER the research team will develop a quick-guide in order to introduce the workshop participants in this creativity technique. Further, the research team wants to define more detailed metrics to measure the application of such techniques in SMEs.

\section{References}

ActionPlanT (2018) https://cordis.europa.eu/docs/projects/cnect/7/258617/080/deliverables/00120120606D32RoadmapContinousValidationReportD32.pdf (Accessed 15 March, 2018).

AgiPlan (2018) Industry 4.0 Roadmap for Companies, https://www.agiplan.de/en/topics/industry40-roadmap-for-companies/ (Accessed 12 June, 2018).

ARTEMIS (2018) European Roadmap for Industrial Process Automation, http://www.processit.eu/ Content/Files/ProcessIT.EU-roadmap_v2_2018_draft-for-comments_final.pdf (Accessed 12 March, 2018).

Aziz, F., Samsudin, S., Nambiar, N., Aziz, U., Li, E. and Zhong, R.Y. (2019) 'Industry 4.0 in New Zealand dairy industry', International Journal of Agile Systems and Management, Vol. 12, No. 2, pp.180-197.

Blackwell, A.F., Phaal, R., Eppler, M. and Crilly, N. (2008) 'Strategy roadmaps: new forms, new practices', International Conference on Theory and Application of Diagrams, Springer, Berlin, Heidelberg, pp.127-140, https://doi.org/10.1007/978-3-540-87730-1_14

Camacho, M. (2016) 'David Kelley: From design to design thinking at Stanford and IDEO', The Journal of Design, Economics, and Innovation, Vol. 2, No. 1, pp.88-101, https://doi.org/10.1016/j.sheji.2016.01.009

Capgemini Consulting (2014) Industry 4.0 - The Capgemini Consulting View, https://www.capgemini.com/consulting/resources/industry4-0/ (Accessed 22 March, 2018).

Ceccacci, S., Matteucci, M., Peruzzini, M. and Mengoni, M. (2019) 'A multipath methodology to promote ergonomics, safety and efficiency in agile factories', International Journal of Agile Systems and Management, Vol. 12, No. 4, pp.407-436.

Cerchione, R. and Esposito, E. (2017) 'Using knowledge management systems: a toxonomy of SMEs strategies', International Journal of Information Management, Vol. 37, No. 1, pp.1551-1562, https://doi.org/10.1016/j.ijinfomgt.2016.10.007

Cho, Y., Yoon, S.P. and Kim, K.S. (2016) 'An industrial technology roadmap for supporting public R\&D planning', Technological Forecasting and Social Change, Vol. 107, pp.1-12, https://doi.org/10.1016/j.techfore.2016.03.006

Curedale, R. (2018) Design Thinking: Process \& Methods Guide, Design Community College Inc., Topanga, CA.

Eckelt, D., Dülme, C., Gausemeier, J. and Hemel, S. (2016) 'Detecting white spots in innovation-driven intellectual property management', Technology Innovation Management Review, Vol. 6, No. 7, pp.34-47, http://doi.org/10.22215/timreview/1003

EFFRA (2016) Factories 4.0 and Beyond: Recommendations for the work Programme 18-19-20 of the FoF PPP under Horizon 2020, http://www.effra.eu/factories-future-roadmap (Accessed 23 February, 2018). 
EPoSS (2018) Strategic Research Agenda of the European Technology Platform on Smart Systems Integration, https:/www.smart-systems-integration.org/public/documents/publications/ EPoSS_SRA2017.pdf (Accessed 23 February, 2018).

Ero, S., Schumacher, A. and Sihn, W. (2016) 'Strategic guidance towards Industry 4.0-a threestage process model', International Conference on Competitive Manufacturing, Vol. 9, pp.495-501.

European Commission (2018) Entrepreneurship and Small and Medium-Sized Enterprises (SMEs), https://ec.europa.eu/growth/smes_de (Accessed 14 August, 2018).

Galvin, R. (1998) 'Science roadmaps', Science, Vol. 280, No. 5365, p.803, https://doi.org/ $10.1126 /$ science. $280.5365 .803 \mathrm{a}$

Ghobakhloo, M. (2018) 'The future of manufacturing industry: a strategic roadmap toward Industry 4.0', Journal of Manufacturing Technology Management, Vol. 29, No. 6, pp.910-936, https://doi.org/10.1108/JMTM-02-2018-0057

Glen, R., Suciu, C., Baughn, C.C. and Anson, R. (2015) 'Teaching design thinking in business schools', The International Journal of Management Education, Vol. 13, No. 2, pp.182-192, http://dx.doi.org/10.1016/j.ijme.2015.05.001

Hermann, M., Pentek, T. and Otto, B. (2016) 'Design principles for industrie 4.0 scenarios', 49th Hawaii International Conference on System Sciences, IEEE, pp.3928-3937, https://doi.org/ 10.1109/HICSS.2016.488

Houben, G., Linie, K. and Vanhoof, K. (1999) 'A knowledge-based SWOT analysis system as an instrument for strategic planning in small and medium sized enterprises', Decision Support Systems, Vol. 26, No. 2, pp.125-135, https://doi.org/10.1016/S0167-9236(99)00024-X

IDEO (2018) Hello, I'm David Kelley, https://www.ideo.com/people/david-kelley (Accessed 14 August, 2018).

IMS2020 (2018) Roadmap on Sustainable Manufacturing, Energy Efficient Manufacturing and Key Technologies, http://data.fir.de/projektseiten/ims2020/files/IMS2020_ActionRoadmap_KAT1-2-3.pdf (Accessed 13 March, 2018).

Innovationszentrum für Industrie 4.0 (2018) Pathfinder i4.0, https://company.i40.de/beratung/ pathfinder-i40 (Accessed 22 May, 2018).

Kagermann, H., Helbig, J., Hellinger, A. and Wahlster, W. (2013) Recommendations for Implementing the Strategic Initiative INDUSTRIE 4.0: Securing the Future of German Manufacturing Industry, Final Report of the Industrie 4.0 Working Group, Forschungsunion.

Karre, H., Hammer, M., Kleindienst, M. and Ramsauer, C. (2017) 'Transition toward an Industry 4.0 state of the LeanLab at Graz University of Technology', Procedia Manufacturing, Vol. 9, pp.206-213, https://doi.org/10.1016/j.promfg.2017.04.006

Koska, A., Gösku, N., Erdem, M.B. and Fettahalioglu, H. (2017) 'Measuring the maturity of a factory for industry 4.0', International Journal of Academic Research in Business and Social Sciences, Vol. 7, No. 7, pp.52-60, https://doi.org/10.6007/IJARBSS/v7-i7/3077

KPMG (2017) How to Plan an Industry 4.0 Strategic Roadmap, https://home.kpmg.com/ uk/en/home/insights/2017/12/how-to-plan-an-industry-4-0-strategic-roadmap.html (Accessed 12 April, 2018).

Lindberg, T., Meinel, C. and Wagner, R. (2011) 'Design thinking: a fruitful concept for it development?', in Plattner, H., Meinel, C. and Leifer, L. (Eds.): Design thinking - Understand - Improve - Apply, Springer, Berlin, Heidelberg, pp.3-18.

Matt, D.T., Orzes, G., Rauch, E. and Dallasega, P. (2020) 'Urban production - a socially sustainable factory concept to overcome shortcomings of qualified workers in smart SMEs', Computers \& Industrial Engineering, Vol. 139, p.105384.

Matt, D.T., Rauch, E. and Riedl, M. (2018) 'Knowledge transfer and introduction of Industry 4.0 in SMEs: a five-step methodology to introduce Industry 4.0', in Brunet-Thornton, R. and Martinez, F. (Ed.): Analyzing the Impacts of Industry 4.0 in Modern Business Environments, IGI Global, Hershey (PA), pp.256-282, https://doi.org/10.4018/978-1-5225-3468-6.ch013 
Merz, S.L. and Siepmann, D. (2016) 'Industrie 4.0-Vorgehensmodell für die Einführung', in Roth, A. (Ed.): Einführung und Umsetzung von Industrie 4.0, Springer Gabler, Berlin, Heidelberg, pp.83-132.

Office of the United States Trade Representative (2017) Small- and Medium-Sized Enterprises (SMEs), https://ustr.gov/trade-agreements/free-trade-agreements/transatlantic-trade-andinvestment-partnership-t-tip/t-tip-12 (Accessed12 October, 2017).

Papetti, A., Pandolfi, M., Peruzzini, M. and Germani, M. (2020) 'A framework to promote social sustainability in industry 4.0', International Journal of Agile Systems and Management, Vol. 13, No. 3, pp.233-257.

Pathfinder (2018) PATHFINDER Roadmap: Defining Research Priorities to Drive R\&D Activities in the Simulation and Forecasting Technologies (S\&FT) Arena, http://pathfinderproject.eu/ downloads/results/Roadmap.pdf (Accessed 26 February, 2018).

Pessl, E., Sorko, S.R. and Mayer, B. (2017) 'Roadmap Industry 4.0-implementation guideline for enterprises', International Journal of Science, Technology and Society, Vol. 5, No. 6, p.193, https://doi.org/10.11648/j.ijsts.20170506.14

Placzek, M., Eberling, C. and Gausemeier, J. (2015) 'Conception of a knowledge management system for technologies', Proceedings of 24th International Association for Management of Technology Conference, 8-11 June, 2015 International Association for Management of Technology (IAMOT), Cape Town, Vol. 24, pp.1646-1663.

Probert, D.R., Farrukh, C.J. and Phaal, R. (2003) 'Technology roadmapping - developing a practical approach for linking resources to strategic goals', Proceedings of the Institution of Mechanical Engineers, Part B: Journal of Engineering Manufacture, Vol. 217, No. 9, pp.1183-1195, https://doi.org/10.1243/095440503322420115

Rauch, E., Dallasega, P. and Matt, D.T. (2017) 'Critical factors for introducing lean product development to small and medium sized enterprises in Italy', Procedia CIRP, Vol. 60, pp.362-367.

Rauch, E., Dallasega, P. and Matt, D.T. (2017) 'Distributed manufacturing network models of smart and agile mini-factories', International Journal of Agile Systems and Management, Vol. 10, Nos. 3-4, pp.185-205.

Santos, C., Mehrsai, A., Barros, A.C., Araújo, M. and Ares, E. (2017) 'Towards Industry 4.0: an overview of European strategic roadmaps', Procedia Manufacturing, Vol. 13, pp.972-979, https://doi.org/10.1016/j.promfg.2017.09.093

Schröder, C. (2017) The Challenges of Industry 4.0 for Small and Medium-Sized Enterprises, Friedrich-Ebert-Stiftung, Bonn.

Seiter, M., Bayrle, C., Berlin, S., David, U., Rusch, M. and Treusch, O. (2016) Roadmap Industrie 4.0: Ihr Weg zur erfolgreichen Umsetzung von Industrie 4.0, Tredition GmbH, Hamburg.

Seram, N. (2013) 'Decision making in product development - a review of the literature', International Journal of Engineering, Vol. 2, No. 4, pp.2305-8269.

Serrat, O. (2017) 'The SCAMPER technique', in Serrat, O. (Ed.): Knowledge Solutions, Springer, Singapore, pp.311-314.

SETIS (2018) Technology Roadmaps, https://setis.ec.europa.eu/implementation/technologyroadmap/technology-roadmaps (Accessed 15 August, 2018).

SPARC (2018) Robotics 2020 Multi-Annual Roadmap, https://www.eu-robotics.net/cms/upload/ downloads/ppp-documents/Multi-Annual_Roadmap2020_ICT-24_Rev_B_full.pdf (Accessed 12 March, 2018).

VDMA (2018) Guideline Industrie 4.0: Guiding Principles for the Implementation of Industrie 4.0 in Small and Medium sized Businesses, https://industrie40.vdma.org/documents/4214230/ 5356229/VDMA+Guideline+Industrie+40.pdf/cd1e8ef0-626e-432d-a2da-5c7a990b1a9b (Accessed 15 August, 2018). 
Vidosav, D.M. (2014) 'Manufacturing innovation and Horizon 2020 - developing and implement 'new manufacturing', Proceedings in Manufacturing Systems, Vol. 9, No. 1, pp.3-8.

Walsh, S. (2004) 'Roadmapping a disruptive technology: a case study - the emerging microsystems and top-down nanosystems industry', Technological Forecasting \& Social Change, Vol. 71, pp.161-185, https://doi.org/10.1016/j.techfore.2003.10.003

Willyard, C.H. and McClees, C.W. (1997) 'Motorola's technology roadmap process', Research Management, Vol. 30, No. 5, pp.13-19, https://doi.org/10.1080/00345334.1987.11757057 